\title{
LEI DE ASSISTÊNCIA TÉCNICA E EXTENSÃO RURAL EM ALAGOAS- BRASIL: CONTRIBUIÇÕES OU DESCONTINUIDADE?
}

\author{
Thacya Clédina da Silva ${ }^{1}$ \\ Francisco Roberto Caporal ${ }^{2}$
}

\begin{abstract}
RESUMO
O objetivo desse artigo foi analisar as contribuições da Lei $n^{0} 12.188 / 2010$ para a agricultura familiar em Alagoas, tomando como base as Chamadas Públicas de Assistência Técnica e Extensão Rural (ATER), lançadas pelo Departamento de Assistência Técnica e Extensão Rural (DATER), da Secretaria de Agricultura Familiar (SAF) do Ministério do Desenvolvimento Agrário (MDA) para o Estado, entre os anos de 2010 a 2014. Tendo a política recente de extensão rural brasileira como pano de fundo, procurou-se entender, através do estudo exploratório, se a operacionalização da Lei poderia melhorar a oferta de serviços e ampliar a abrangência em número de beneficiários. Em Alagoas, em 2006, segundo o IBGE, 92\% dos agricultores não receberam assistência técnica, ou seja, o Estado encontrava-se em condições críticas no atendimento dessa política. Entretanto, ao término desta pesquisa, ficou evidenciado que, através das Chamadas Públicas, foi atendido apenas $4 \%$ do universo da agricultura familiar, e que as promessas dos gestores públicos, que seriam de desburocratização e de continuidade do serviço com a implementação da Lei, não se efetivaram nesse Estado.
\end{abstract}

Palavras-chave: chamadas públicas de ATER, extensão rural, políticas públicas.

\section{LAW OF TECHNICAL ASSISTANCE AND RURAL EXTENSION IN ALAGOAS- BRAZIL: CONTRIBUTIONS OR DISCONTINUITY?}

\begin{abstract}
The aim of this study was to analyze the contributions of Law 12,188 / 2010 to the family farm in Alagoas, based on the Public Technical Assistance Calls and Rural Extension (ATER), launched by the Department of Technical Assistance and Rural Extension (DATER) of Department of Family Agriculture (SAF) of the Ministry of Agrarian Development (MDA) for the state between the years 2010 to 2014. With the recent policy of the Brazilian rural extension as a backdrop, we tried to understand through this exploratory study, how the implementation of the Law could improve the
\end{abstract}

${ }^{1}$ Graduada em Zootecnia. Mestre em Extensão Rural e Desenvolvimento Local (UFRPE). E-mail: thacya.zte@bol.com.br

${ }^{2}$ Graduado em Agronomia. Mestre em Extensão Rural. Doutor em Agroecologia, Campesinato e História. Professor do Programa de Pós-Graduação em Extensão Rural e Desenvolvimento Local (Posmex), da Universidade Federal Rural de Pernambuco (UFRPE). E-mail: caporalfr@gmail.com. 
service offered and expand the scope of the number of beneficiaries. In Alagoas, in 2006, according to IBGE, $92 \%$ of farmers did not receive technical assistance, that is, because the state was in critical condition in compliance with this policy. However, at the end of this research, it became evident that the service through the Public Call, had reached $4 \%$ of the universe of family farming, and that the promises of the public managers which would be to reduce bureaucracy and continuity of service by the implementation of this law, had not had any affect in this state.

Keywords: Agricultural extension, public call ATER, public policy.

\section{INTRODUÇÃO}

Este trabalho se propõe a analisar as contribuições do Governo Federal para as ações de Assistência Técnica e Extensão Rural (ATER) no Estado de Alagoas, voltadas à agricultura familiar, após a Lei no 12.188 de janeiro de 2010, ano em que se começa a atuar com Chamadas Públicas para a contratação desses serviços no Brasil, tendo como referência as Chamadas Públicas lançadas pelo Departamento de Assistência Técnica e Extensão Rural (DATER), da Secretaria de Agricultura Familiar (SAF) do Ministério de Desenvolvimento Agrário (MDA) para o estado de Alagoas, no período de 2010-2014.

Em Alagoas, segundo menor estado do Brasil, lócus da pesquisa, a reivindicação de universalização da oferta de assistência técnica e extensão rural tem sido uma constante de todos os movimentos sociais e sindicais do campo. Tal demanda parece estar fortemente alicerçada na realidade, pois, em 2006, o Censo Agropecuário, realizado pelo Instituto Brasileiro de Geografia e Estatística (IBGE), mostrou que o Estado possui 123.331 estabelecimentos agropecuários, e, destes, 91\% (111.751) são estabelecimentos da agricultura familiar, com destaque para: camponeses, assentados de reforma agrária, indígenas, quilombolas e agricultores tradicionais.

Ainda de acordo com o censo, há 326.135 pessoas ocupadas na agricultura familiar e $92 \%$ desse total de agricultores não receberam assistência técnica em Alagoas, demonstrando a precariedade de atendimento ao setor que mais ocupa mão de obra no Estado. Apenas $8 \%$ desse público afirma receber os serviços. (IBGE, 2006).

O histórico da ATER em Alagoas, quanto à implantação dos serviços de extensão rural, é semelhante ao nacional, iniciando com Associação Nordestina de Crédito e Assistência Técnica e, posteriormente, com a Empresa Estadual de Assistência técnica e Extensão Rural (EMATER). A partir da década de 1980, as medidas neoliberais passaram a se apor no aparelho público estadual e, nesse período, havia a perspectiva de extinção de diversas empresas públicas.

O fim da Empresa Brasileira de ATER (EMBRATER) ocorreu em 1990, provocando a interrupção dos serviços. Os estados brasileiros com menores arrecadações, especialmente nas regiões Norte e Nordeste, foram os que mais sofreram com essas novas medidas (PRADO, 2006). Em Alagoas, a EMATER foi incorporada à Secretaria Estadual de Agricultura, com uma reduzida equipe de funcionários, resultando numa limitação extrema do serviço prestado. (LIRA, 2014).

A partir de 2003, o Ministério do Desenvolvimento Agrário (MDA) iniciou o processo de reestruturação da assistência técnica e extensão rural através da implementação da Política Nacional de ATER- PNATER, e, em janeiro de 2010, foi promulgada a Lei $\mathrm{n}^{\circ}$ 12.188, conhecida como Lei de ATER. Segundo a Lei, em seu artigo $2^{\circ}$, Item I, entende-se por Assistência Técnica e Extensão Rural - ATER: 
serviços de educação não formal e de caráter continuado, no meio rural. Já em seu artigo $3^{\circ}$, quando estabelece os princípios da PNATER, o legislador assegura, no segundo princípio, que a política de ATER deve garantir "gratuidade, qualidade e acessibilidade" para os agricultores familiares e assentados da reforma agrária, assim como ao conjunto de "beneficiários" descritos no artigo $5^{\circ}$ da Lei.

Considerando o acima exposto, este estudo tem como objetivo examinar os problemas enfrentados na implementação dos projetos de ATER, oriundos de Chamadas Públicas em relação à acessibilidade e continuidade dos serviços oferecidos para os agricultores familiares de Alagoas, bem como apresentar um conjunto de proposições analisadas pelos atores dessa pesquisa no Estado.

A pergunta que se quer responder é a seguinte: dadas as "promessas" dos gestores públicos e os dispositivos da Lei, houve incremento no número de beneficiários e continuidade nos serviços de ATER realizados no Estado de Alagoas, com o apoio do Governo Federal?

O presente trabalho foi desenvolvido a partir de pesquisa exploratória (VASCONCELOS, 2007; GIL, 2010), utilizando no itinerário metodológico: o estudo de campo e a pesquisa documental da Lei de ATER, decretos e documentos que orientam a PNATER, assim como as Chamadas Públicas lançadas para o serviço de ATER, em Alagoas, de 2010 a 2014. No trabalho de campo, adotou-se o procedimento da técnica de entrevista aberta.

$\mathrm{Na}$ amostra de onze (11) entrevistas, buscou-se garantir a participação do maior número possível dos seguimentos envolvidos: instituição contratante (MDADelegacia Federal do Desenvolvimento Agrário em Alagoas- DFDA), instituições executoras (EMATER, Associação de Orientação as Cooperativas do NordesteAssocene, Instituto Naturagro, ONG Movimento Minha Terra e o Centro de Capacitação Zumbi dos Palmares), além do Conselho de Desenvolvimento Rural Sustentável (CEDAFRA), instituições de representação da agricultura familiar (Federação dos Trabalhadores na Agricultura do Estado de Alagoas - FETAG e Movimento Sem Terra - MST), e instituição de representações dos técnicos (Sindicato dos Trabalhadores do Setor Público Agrícola e Ambiental de AlagoasSINDAGRO). Nas entrevistas, procurou-se dialogar com os representantes legais das instituições ou técnicos referendados por esses, tendo as entrevistas sido gravadas/transcritas e as respostas analisadas à luz do que se propunha com a Lei de ATER.

O artigo se organiza da seguinte forma: inicialmente, traz uma apresentação da história recente da Política Nacional de Extensão Rural e das promessas dos gestores à época da promulgação da Lei de ATER; em seguida, os autores analisam as Chamadas Públicas de Projetos de ATER, no intervalo temporal de 2010 a 2014 para o estado de Alagoas, como também a dinâmica de execução desses projetos e as recomendações realizadas pelas instituições entrevistadas diante das dificuldades enfrentadas nesse processo. $E$, por fim, traz as considerações finais do trabalho, evidenciando os achados da pesquisa. 


\title{
2. POLÍTICA DE EXTENSÃO RURAL: HISTÓRIA RECENTE E PROMESSAS A RESPEITO DA LEI DE ATER
}

A função do Estado é promover o bem-estar da sociedade e para atingir esses resultados, os governos se utilizam das Políticas Públicas (RUA, 2005). Flexor e Leite definem Política Pública como:

\begin{abstract}
Um sistema de decisões públicas que visa a ações ou omissões, preventivas ou corretivas, destinadas a manter ou modificar a realidade de um ou de vários setores da vida social, por meio da definição de objetivos e estratégias de atuação e da alocação dos recursos necessários para atingir os objetivos estabelecidos (FLEXOR; LEITE, 2006).
\end{abstract}

Bonnal e Kato (2011) alertam que as políticas públicas se encontram inseridas em contextos políticos e sociais específicos e são disputadas por diferentes atores com interesses diversificados e distintos graus de poder de influência e cooptação. (BONNAL; KATO, 2011).

Década após década, com diferentes formatos institucionais e abordagens na medida em que foi estruturada, a política pública de ATER participou ativamente do processo de desenvolvimento rural. Primeiro, supervisionando crédito e levando conhecimento para a produção agrícola e economia doméstica, visando o bem-estar das famílias e, em seguida, transferindo as técnicas da chamada Revolução Verde (adubos químicos, sementes melhoradas, agrotóxicos), visando modernizar a agricultura e massificando o crédito rural orientado para produção de commodities (PRADO, 2006).

Em 2003, assume no cenário nacional um projeto político que, segundo Mattei (2010), se dizia democrático e popular, baseado na força das organizações sociais e em partidos políticos conectados com demandas populares. O autor afirma que isso significou uma mudança de rota na intervenção do estado e das políticas públicas, gerando grandes expectativas nos segmentos sociais rurais (MATTEI, 2010). A primeira ação do Governo Federal referente a ATER foi a elaboração da nova Política Nacional de Assistência Técnica e Extensão Rural (PNATER), a partir de diversas consultas e diálogos com os segmentos da agricultura familiar no país (CAPORAL, 2006).

Segundo Dias (2008), a nova PNATER preconizava a (re)orientação das concepções, métodos e princípios pela agroecologia, a universalidade, a gratuidade e o caráter público dos serviços de ATER, destinado prioritariamente a um público específico - a agricultura familiar. Conforme Caporal (2009), com o surgimento da PNATER, a tarefa de educação na extensão rural assumiu uma dimensão complexa, ampla e profunda, pois se estabeleceram, a partir de então, novos paradigmas e estes exigem novas estratégias e novas bases pedagógicas nas atividades de formação, que possam se refletir na práxis dos Agentes extensionistas, sob pena de criar um descompasso entre discurso e prática da Extensão Rural.

Apesar dos avanços alcançados com a implementação da PNATER, alguns problemas precisavam ser enfrentados no sentido de consolidar a ATER no Brasil, especialmente no que se refere à institucionalização da política. Contudo, ao contrário dos processos de diálogo anteriores, todos os agentes de ATER foram surpreendidos com o lançamento, pelo Governo Federal, de uma proposta de Lei (Projeto de Lei no 5.665, de 2009) encaminhada ao Congresso Nacional em caráter de urgência (CAPORAL, 2011). Segundo Diniz et al. (2011, p.5), "Nem mesmo os representantes do Comitê de ATER (Conselho Nacional de Desenvolvimento Rural 
Sustentável - CONDRAF) sabiam do teor da proposta que foi escrita a poucas mãos e com nenhuma participação ativa da sociedade civil".

Em 11 de janeiro de 2010, foi sancionada a Lei $n^{\circ}$ 12.188. Destaque-se o seu Artigo $5^{\circ}$, definindo que a contratação de serviços de ATER "será antecedida de Chamada Pública, destinada a classificar propostas técnicas apresentadas pelas Entidades Executoras" (BRASIL, 2010). São as chamadas, portanto, mecanismo jurídico-legal que, a partir desse momento, passam a definir a localização geográfica, o público a ser beneficiado, os valores disponibilizados, enfim, as ações de ATER a serem financiadas pelo Governo Federal e executadas por meio de diversas entidades.

Diniz et al. (2011); Caporal (2011) e Teixeira (2009) analisaram que o processo da construção do Projeto de Lei desconsiderou a construção coletiva que havia ocorrido na elaboração da PNATER de 2003, e que o projeto foi feito a poucas mãos e sem consulta à sociedade. Além disso, segundo Caporal (2011), a Lei eliminou a Agroecologia do texto. Na opinião do autor, "esses fatores contribuíram para que a Pnater de 2010 desde seu berço trouxesse o estigma de ser responsável por um retrocesso no campo da extensão rural contemporânea" (CAPORAL, 2011, p.24).

Não obstante, a história mostra outras contradições, pelo menos é o que se pode deduzir de algumas manifestações de gestores públicos. Assim, durante a reunião para apresentação do Projeto de Lei (PL), no dia 12 de setembro de 2009, na Câmara dos Deputados, conforme publicado no site do MDA, o ministro Guilherme Cassel afirmou sobre o PL ter sido: "Um projeto de lei de difícil construção, ousado, que abre a possibilidade de prestação de serviços de ATER com mais qualidade." ${ }^{2} \mathrm{Na}$ mesma ocasião, o então diretor do Departamento de Assistência Técnica e Extensão Rural (DATER) da Secretaria de Agricultura Familiar do MDA, Argileu Martins da Silva declarou que: "o projeto dialoga com a dinâmica da agricultura familiar".

O então Ministro do Desenvolvimento Agrário, Guilherme Cassel, afirmava, em 2010, que, com a aprovação da Lei, "será fomentado o desenvolvimento rural sustentável da agricultura familiar e dos assentamentos da reforma agrária sem interrupções". Segundo o Ministro (à época):

\begin{abstract}
Vamos fazer isso de forma mais transparente, com a contratação, por meio de Chamadas Públicas, de entidades que sejam capazes de prestar os serviços. Também vamos ter mais celeridade, porque pagaremos por serviços prestados. Com isso, não haverá mais problemas de interrupção dos serviços para a celebração de novos convênios, gerando a falta de continuidade ${ }^{3}$.
\end{abstract}

Segundo a Revista de Extensão Rural da Universidade Federal de Santa Maria, publicada em 2003, no artigo "Bases para uma nova ATER pública", Caporal já havia alertado que "a nova ATER pública atuará num ambiente conflitivo, pois a transição para o desenvolvimento sustentável será um processo político intenso." (CAPORAL, 2003). Os estudos de Diesel et al. (2015) afirmaram que o enfraquecimento do compromisso político do governo com novos assentamentos de reforma agrária, o fortalecimento dos interesses de setores do agronegócio e a perda de força dos discursos críticos ao modelo de agricultura industrial, tornou a

\footnotetext{
${ }^{2}$ Disponível em: <http://www.mda.gov.br/sitemda/noticias/mda>. (Acesso em: 30/05/2014).

${ }^{3}$ Disponível em: <http://www.mda.gov.br/sitemda/noticias/mda>. (Acesso em: 30/05/2014).
} 
conjuntura política desfavorável a um projeto de desenvolvimento rural em favor da agricultura familiar. Essa realidade apontada pelos autores pode auxiliar a compreensão de alguns desdobramentos na execução das Chamadas Públicas de ATER em Alagoas.

\section{CHAMADAS PÚBLICAS DE PROJETOS DE ATER DE 2010 A 2014 PARA ALAGOAS}

Segundo os dispositivos da Lei $\mathrm{n}^{0}$ 12.188/2010, duas mudanças essenciais no serviço de ATER são definidas: novas formas de contratação - via Chamadas Públicas - e nova forma de credenciamento dos prestadores de serviço. A execução dos serviços de ATER dar-se-á por meio das instituições credenciadas nos Conselhos Estaduais de Desenvolvimento Rural Sustentável e selecionadas por análise de projetos submetidos às Chamadas Públicas. As Chamadas estão basicamente estruturadas da seguinte forma: objeto; entidades executoras; público beneficiário; área geográfica de atuação; ações e atividades; metodologia; prazo de execução do serviço; remuneração do serviço; qualificação da equipe técnica; prazos; objetivos da seleção; e, a validade das propostas.

Entre os anos de 2010 a 2014 foram lançadas pelo MDA para Alagoas, dezesseis (16) Chamadas Públicas de projetos de ATER, contendo vinte e dois (22) lotes. Desse total de 16 Chamadas Públicas, cerca de $9 \%$ conseguiram concluir todas as metas previstas.

O público-alvo dos projetos foi prioritariamente os agricultores que estão inseridos na política de Territórios de Cidadania. O segundo público em destaque foi os beneficiários do Programa Brasil Sem Miséria (PBSM), com cerca de $23 \%$ dos lotes, sendo que uma (1) dessas Chamadas foi destinada para o público específico dos agricultores quilombolas, que estão situados na linha de pobreza extrema.

Cerca de $40 \%$ das Chamadas divulgadas não lograram êxito para contratação de entidades, sendo que $23 \%$ desse total foram devido à ausência de projetos, dando "vazio" ou "em branco", como se diz no jargão do MDA. Aproximadamente $14 \%$ dos lotes tiveram projetos apresentados e instituição selecionada, porém não efetivaram os contratos por uma deficiência interna do MDA: não havia fiscais disponíveis para acompanhar a execução. Por conta disso, 3.240 possíveis beneficiários foram prejudicados. Segundo representante da DFDAAL (gestão 2003/2011):

\footnotetext{
É tanta falta de fiscal, que o fiscal de Alagoas é suplente do fiscal de Aracaju e vice-versa. Então alguns momentos ele vai ter, que não só tratar de Alagoas, mas vai ter que ir a Sergipe ajudar. Lógico que a gente sabe que todos os órgãos fazem isso, mas quando todo mundo tem pouco, aí falta para todo mundo (ENTREVISTADO DA DFDA-AL).
}

Entre os anos de 2010 a 2014 ocorreu um declínio do número de Chamadas Públicas para o estado, conforme se pode observar no gráfico abaixo: 
Gráfico 1 - Chamadas Públicas de ATER, para Alagoas, de 2010 a 2014

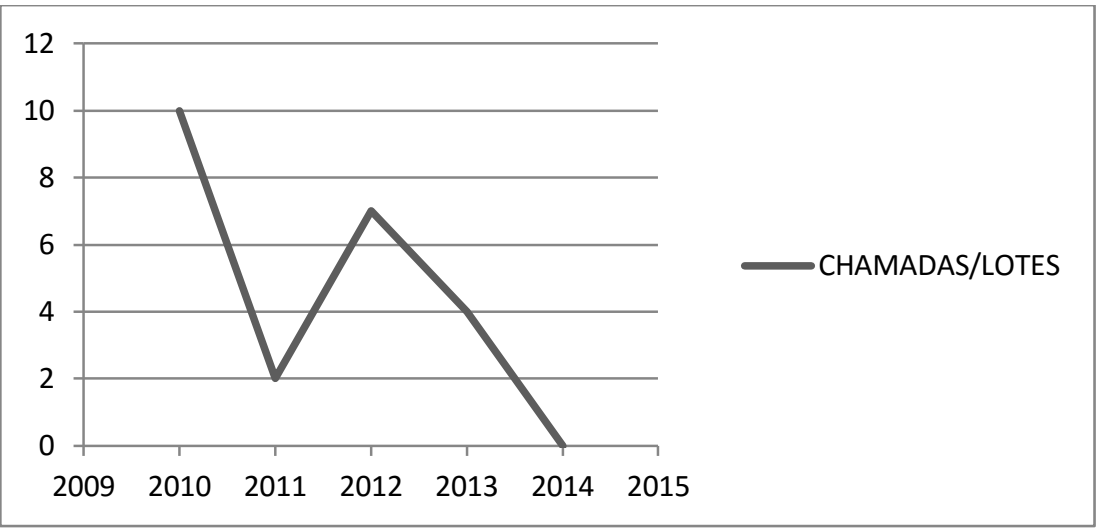

Fonte: elaborado pelos autores

Entre 2010 e 2011 houve uma diminuição de 80\% das Chamadas, possivelmente justificada devido às dificuldades de execução dos projetos do primeiro ano. A situação se agravou em 2014, ano em que, de acordo com os dados disponibilizados pela SAF/MDA, não houve nenhuma chamada de ATER para o Estado, provavelmente pelo cenário político de redução orçamentária para o MDA.

Os projetos contratados pelo MDA e a situação do contrato, no período da pesquisa, podem ser verificados na tabela abaixo. 
Quadro 1- Projetos contratados em Alagoas

\begin{tabular}{|c|c|c|c|c|c|c|}
\hline Chamada & Lote & $\begin{array}{l}\text { Público- } \\
\text { Alvo }\end{array}$ & $\begin{array}{c}\text { Entidade } \\
\text { Selecionada }\end{array}$ & $\begin{array}{c}\text { № } \\
\text { benef. }\end{array}$ & $\mathbf{R} \$$ & Situação do contrato \\
\hline $95 / 2010$ & 1 & $\begin{array}{l}\text { TC } \\
\text { Agreste }\end{array}$ & $\begin{array}{l}\text { Instituto } \\
\text { Naturagro }\end{array}$ & 1.620 & $1.179 .005,55$ & $\begin{array}{l}\text { Execução parcial, } \\
\text { contrato suspenso }\end{array}$ \\
\hline $95 / 2010$ & 2 & $\begin{array}{l}\text { TC } \\
\text { Agreste }\end{array}$ & $\begin{array}{l}\text { Instituto } \\
\text { Naturagro }\end{array}$ & 1.620 & $1.179 .005,55$ & $\begin{array}{l}\text { Execução parcial, } \\
\text { contrato suspenso }\end{array}$ \\
\hline $95 / 2010$ & 3 & $\begin{array}{l}\text { TC } \\
\text { Agreste }\end{array}$ & $\begin{array}{l}\text { Instituto } \\
\text { Naturagro }\end{array}$ & 1.080 & $786.283,43$ & $\begin{array}{l}\text { Execução parcial, } \\
\text { contrato suspenso }\end{array}$ \\
\hline $121 / 2010$ & 1 & $\begin{array}{l}\text { TC Bacia } \\
\text { Leiteira }\end{array}$ & $\begin{array}{l}\text { Instituto } \\
\text { Naturagro }\end{array}$ & 1.080 & $777.100,71$ & $\begin{array}{l}\text { Execução parcial, } \\
\text { contrato suspenso }\end{array}$ \\
\hline $02 / 2011$ & 1 & $\begin{array}{l}\text { Programa } \\
\text { Brasil } \\
\text { Sem } \\
\text { Miséria } \\
\text { (PBSM) }\end{array}$ & $\begin{array}{l}\text { Movimento } \\
\text { Minha Terra } \\
\text { (MMT) }\end{array}$ & 1.120 & $1.185 .246,19$ & Contrato encerrado \\
\hline $04 / 2011$ & 10 & DTAB & $\begin{array}{l}\text { Movimento } \\
\text { Minha Terra } \\
\text { (MMT) }\end{array}$ & 720 & $816.239,53$ & Contrato encerrado \\
\hline $02 / 2012$ & 2 & $\begin{array}{l}\text { Programa } \\
\text { Brasil } \\
\text { Sem } \\
\text { Miséria } \\
\text { (PBSM) } \\
\text { Sertão }\end{array}$ & $\begin{array}{l}\text { Centro de } \\
\text { Capacitação } \\
\text { Zumbi dos } \\
\text { Palmares }\end{array}$ & 3.000 & $4.602 .821,00$ & $\begin{array}{l}\text { Contrato vigente em } \\
\text { execução }\end{array}$ \\
\hline $09 / 2012$ & 1 & $\begin{array}{l}\text { Programa } \\
\text { Brasil } \\
\text { Sem } \\
\text { Miséria } \\
\text { (PBSM) } \\
\text { Quilom- } \\
\text { bolas }\end{array}$ & $\begin{array}{l}\text { Associação de } \\
\text { Orientação as } \\
\text { Cooperativas } \\
\text { do Nordeste - } \\
\text { Assocene }\end{array}$ & 1.400 & $3.162 .899,22$ & $\begin{array}{l}\text { Contrato vigente em } \\
\text { execução }\end{array}$ \\
\hline $010 / 2012$ & 1 & $\begin{array}{l}\text { Susten- } \\
\text { tabilidade }\end{array}$ & Emater & 1.920 & $6.763 .916,15$ & $\begin{array}{l}\text { Contrato vigente em } \\
\text { execução }\end{array}$ \\
\hline $011 / 2012$ & 1 & PNCF & $\begin{array}{l}\text { Cooperativa } \\
\text { Agropecuária } \\
\text { Regional de } \\
\text { Palmeira dos } \\
\text { Índios LTDA- } \\
\text { Carpil }\end{array}$ & 1.000 & $3.467 .839,21$ & $\begin{array}{l}\text { Contrato vigente em } \\
\text { execução }\end{array}$ \\
\hline $07 / 2013$ & 7 & $\begin{array}{l}\text { Sust. } \\
\text { Cadeia } \\
\text { produtiva } \\
\text { do leite }\end{array}$ & Emater & 1.500 & $5.084 .549,86$ & $\begin{array}{l}\text { Contrato vigente em } \\
\text { execução }\end{array}$ \\
\hline $010 / 2013$ & 1 & $\begin{array}{l}\text { Mulheres } \\
\text { rurais }\end{array}$ & Emater & 240 & $704.245,30$ & $\begin{array}{l}\text { Contrato vigente em } \\
\text { execução }\end{array}$ \\
\hline $011 / 2013$ & 13 & $\begin{array}{l}\text { Programa } \\
\text { Brasil } \\
\text { Sem } \\
\text { Miséria } \\
\text { (PBSM) }\end{array}$ & $\begin{array}{l}\text { Movimento } \\
\text { Minha Terra } \\
\text { (MMT) }\end{array}$ & 1.600 & $4.991 .006,28$ & $\begin{array}{l}\text { Contrato vigente em } \\
\text { execução }\end{array}$ \\
\hline $011 / 2013$ & 14 & $\begin{array}{l}\text { Programa } \\
\text { Brasil } \\
\text { Sem } \\
\text { Miséria } \\
\text { (PBSM) }\end{array}$ & $\begin{array}{l}\text { Movimento } \\
\text { Minha Terra } \\
\text { (MMT) }\end{array}$ & 1.400 & $2.322 .480,74$ & $\begin{array}{l}\text { Contrato vigente em } \\
\text { execução }\end{array}$ \\
\hline
\end{tabular}

Fonte: elaborado pelos autores

No período, foram lançadas onze (11) Chamadas com projetos contratados pelo MDA, distribuídas em quatorze (14) lotes, com seis (6) instituições contratadas. O Instituto de Inovação para o Desenvolvimento Rural Sustentável (EMATER-AL) é a única instituição que, até o momento da pesquisa, não havia 
conseguido executar nenhuma das metas previstas nas Chamadas 010/2012, 010/2013, 07/2013. O principal motivo do Estado não ter conseguido executar as Chamadas, pode estar atrelado ao reduzido quadro técnico que a instituição dispõe. Neste sentido, o entrevistado do Sindagro afirma que:

O Governo Federal através de convênios conseguiu contribuir na estruturação da Emater (carros, computadores, etc.), mas o estado não fez a contrapartida dele que era contratar as pessoas. O que comprometeu as chamadas em si. E o estado não conseguiu executar as chamadas (ENTREVISTADO DO SINDAGRO).

Os contratos efetivados pelo MDA, com as seis instituições antes mencionadas, envolvem um montante financeiro de $\mathrm{R} \$ 33.022 .638,72$ e um público potencial de 19.300 beneficiários. Conforme dados enviados pela Secretaria de Agricultura Familiar (SAF), através do Departamento de Assistência Técnica (DATER), observa-se que até a data da pesquisa foram cadastrados e "atendidos" 12.948 agricultores, segundo consta no sistema de ATER (SIATER). Ou seja, através dos projetos contratados estão sendo "atendidos" cerca de $4 \%$ dos agricultores familiares de Alagoas.

Esse "atendimento" nem sempre significa assistência técnica e extensão rural, de fato. Representa, apenas, que esse público foi beneficiário de algumas das metas de determinado projeto. Do total de beneficiários, em cinco (5) anos de execução de projetos contratados a partir das Chamadas Públicas de ATER, 6.547 são mulheres e 6.401 são homens, distribuídos em sessenta e três (63)dos cento e dois (102) municípios de Alagoas, sendo que em apenas dez (10) municípios estão concentrados 5.769 dos agricultores/as beneficiados. Ou seja, em dez (10) dos municípios atendidos, estão aproximadamente $45 \%$ do total de beneficiários do estado inteiro. Nos outros cinquenta e três (53) municípios se observa uma pulverização do público cadastrado. Assim, em quase $15 \%$ dos municípios, o número de beneficiários não passa de dez (10).

O percentual de $4 \%$ de agricultores atendidos através dos projetos oriundos de Chamadas Públicas de ATER está longe de ser uma amostra possível de provocar a revolução alardeada pelo então deputado Pedro Eugênio, um dos relatores do PL de ATER, em 2009. Disse o mesmo: "Será uma revolução em nosso País". Na mesma linha, o então secretário da Secretaria de Agricultura Familiar (SAF), em dezembro de 2010, Adoniram Sanches Peraci, no encontro que discutiu "Avanços da Política Nacional de ATER", anunciou que "o sistema de extensão está chegando aonde nunca se chegou". Em Alagoas, como mostram os dados, tal fato está longe de acontecer.

As Chamadas 02 e 04/2011 foram finalizadas e, apesar da mesma entidade (MMT) ter sido selecionada por outra Chamada para trabalhar com o mesmo público e na mesma região, não há possibilidade de continuidade dos serviços. O PBSM prevê que, com o fim da execução do contrato e do pagamento do fomento às famílias assessoradas, o estado responsabilizar-se-ia por assumir esse público. Entretanto, em Alagoas não existe um sistema estadual de ATER que possa dar seguimento à ação inicial do Governo Federal, que, por sua vez, não autoriza a continuação do serviço na mesma área, nesses casos.Sobre isso o representante do MMT fez o seguinte comentário:

Concluímos essas chamadas e por sorte surgiram outras chamadas e a gente ganhou. Inclusive uma delas é na mesma área (região agreste) embora o público seja outro. O que é uma 
das falhas gritantes desse processo, o fato de não podermos dar continuidade aos serviços de ATER com o público já atendido anteriormente pela instituição (ENTREVISTADO DO MMT).

Uma das grandes preocupações apresentadas pelo representante da Federação dos Trabalhadores da Agricultura (FETAG) sobre ATER é referente à (des) continuidade do serviço. O mesmo afirmou que os contratos são feitos com prazos determinados, não havendo uma continuidade, e esclarece: "Porque às vezes o agricultor tem uma cultura de dois anos e o técnico é contratado por um tempo menor. A expectativa não é atendida e os resultados não são visualizados" (ENTREVISTADO DA FETAG).

Esse achado confirma a hipótese levantada por Caporal (2014), no capítulo intitulado Extensão Rural como Política Pública: a difícil tarefa de avaliar, do livro Políticas agroambientais e sustentabilidade: desafios, oportunidades e lições aprendidas, IPEA, 2014, onde o autor diz:

\begin{abstract}
A Lei de ATER inclui promessas que não poderão ser cumpridas. Isto começa já na definição de ATER, em que se lê que se trata de um serviço de educação não formal, de caráter continuado. Ora, a debilidade orçamentária e as formas instituídas de contratação de serviços a partir de chamadas públicas de projetos mostraram, já nos dois primeiros anos de vigência da Lei, a inviabilidade de garantir a continuidade. Isto é, não havendo recursos para universalizar a oferta de serviços de ATER, o MDA devera sempre fazer escolhas de localidades em que os agricultores serão assistidos. Por um lado, caso se mantenham sempre os mesmos territórios, excluem-se agricultores de outros territórios de forma permanente. Por outro lado, ao se elegerem territórios diferentes, cria-se a descontinuidade (CAPORAL, 2014, p. 41- 42).
\end{abstract}

A análise das Chamadas Públicas lançadas para Alagoas, de 2010 a 2014, já aponta a direção de que esse instrumento está apresentando dificuldades estruturais em sua materialização para o cumprimento do que foi estabelecido pela Lei de ATER. Para melhor compreensão desses problemas foi realizada uma análise das dinâmicas pós-contrato, vividos pelas instituições executoras, como também procurou-se registrar o conjunto de proposições feitas pelos atores dessa política pública em Alagoas.

\title{
4. DINÂMICA DE EXECUÇÃO DOS PROJETOS CONTRATADOS E RECOMENDAÇÕES
}

$\mathrm{Na}$ dinâmica pós-contrato foram diagnosticados diversos problemas na execução dos projetos pelas entidades contratadas, e o primeiro foi referente à composição e qualificação da equipe técnica. As instituições identificam que o longo intervalo entre a seleção do projeto e o início da execução provoca desistência de técnicos e a necessidade de substituição. Além desta desistência inicial, é observada alta rotatividade dos técnicos durante toda a execução dos projetos. Segundo as instituições, isso ocorre devido à demora na autorização das mudanças solicitadas, demora na contratação e nomeação do fiscal e longo período para o início da execução do projeto.

Porém, na opinião dos técnicos, tal fato se deve aos atrasos dos pagamentos dos salários, descontinuidade dos serviços e, principalmente, devido às 
condições precárias de trabalho (estruturais, operacionais e legais), associadas ao não cumprimento da legislação trabalhista. Segundo os técnicos, isso ocorre pela falta de fiscalização por parte dos órgãos competentes. (Depoimentos de Técnicos extensionistas, do Curso de Especialização em Residência Agrária, à pesquisadora).

Sobre esse assunto, Caporal (2014, p. 41) apresentou a seguinte hipótese:

De que havia a possibilidade de que parte dos recursos contratados pudesse servir para reforçar o caixa das entidades de ATER. Como o custo calculado pelo DATER para pagar os serviços incorpora um valor de salário correspondente a 8,5 salários mínimos para técnicos de nível superior e $60 \%$ deste valor para técnicos de nível médio, e as entidades de ATER, por sua vez, salvo raras exceções, não pagam este valor de salário aos seus técnicos, sobraria uma margem de dinheiro líquido para estas (...) Este tipo de possibilidade foi um dos atrativos para que muitas entidades aderissem à proposta de política do MDA/SAF/Dater [grifos nossos].

Na sequência operacional, após a celebração do contrato, as instituições devem aguardar a ordem de serviço emitida pelo MDA. Nessa fase, foi identificado um descompasso de informações entre o DATER/SAF/ MDA e a Delegacia Federal do Desenvolvimento Agrário em Alagoas (DFDA-AL). Por diversas vezes, a ordem de serviço foi emitida à instituição executora sem que a delegacia estadual houvesse sido informada (ENTREVISTADO DO MMT).

A instituição também foi liberada para iniciar as atividades sem que os técnicos envolvidos no projeto estivessem aptos para utilizar o Sistema de ATER (SIATER), que é um sistema onde é cadastrada e comprovada, através de atestes liberados pelo próprio sistema, a realização das metas previstas. Dessa forma, os técnicos foram a campo sem os atestes, necessitando de retrabalho e aumento nos custos para realizar a atividade de seleção de famílias (ENTREVISTADO DO INSTITUTO NATURAGRO).

A instituição que teve todos os contratos suspensos alegou que diversos problemas colaboraram, como, por exemplo, a falta de estrutura de pessoal e de internet da delegacia para o uso do Siater por parte dos fiscais, que, segundo eles, provocou uma morosidade no processo de análise da prestação de contas. Assim, o primeiro lote enviado para análise demorou quatro meses para ser avaliado. $E$ tendo em vista que a instituição só recebe após prestar conta das atividades realizadas, a instituição não conseguiu realizar o pagamento dos técnicos. Tudo isso contribuiu para a rotatividade do corpo técnico e comprometeu a "qualidade" do trabalho (ENTREVISTADO DO INSTITUTO NATURAGRO).

Por sua vez, a ONG Movimento Minha Terra (MMT) alega, como dificuldade inicial:

\begin{abstract}
Ausência de reunião da entidade contratada com o fiscal do MDA, ou gestor do contrato; reunião com a Delegacia do MDA; reunião sobre SIATER e questões relativas à execução do contrato, para esclarecimentos, fortalecimento das parcerias institucionais, etc. (ENTREVISTADO DO MMT).
\end{abstract}

No início da execução, as entidades se depararam com limitações na divulgação, ausência de instrumentos de divulgação e informação sobre a atuação do MDA no Estado. Segundo um entrevistado do MMT: "É preciso dar visibilidade 
para o que está sendo realizado", alegando que um instrumento midiático pode colaborar com o processo de sensibilização e mobilização dos futuros beneficiários.

$\mathrm{Na}$ etapa de identificação e seleção do público-alvo, as instituições deverão sensibilizar os possíveis beneficiários, sendo esta uma etapa fundamental e difícil, conforme avaliam os representantes das entidades que foram entrevistados. No caso das entidades executoras de projetos para o público do PBSM, eles afirmam que recebem uma lista do Governo Federal com possíveis beneficiários. Entretanto, houve demora na disponibilização da lista e desatualização dos dados básicos fornecidos pelo Governo à entidade executora, provocando falhas e retrabalho (ENTREVISTADOS DA NATURAGRO, MMT, ASSOCIAÇÃO DE ORIENTAÇÃO ÀS COOPERATIVAS DO NORDESTE-ASSOCENE E CENTRO DE CAPACITAÇÃO ZUMBI DOS PALMARES).

Além disso, os agricultores só podem ser beneficiários do projeto de ATER se forem portadores da Declaração de Aptidão ao Pronaf (DAP) ou constarem na relação de beneficiários (RB), emitida pelo INCRA, para os agricultores assentados da Reforma Agrária. Muitos agricultores familiares no estado de Alagoas não possuem a DAP, o que levou o entrevistado da Assocene a afirmar que:

Outra dificuldade que é identificada é o processo de emissão de DAP e do NIS, diante da grande demanda de famílias quilombolas que ainda não acessavam as políticas públicas. Os órgãos credenciados para a emissão dessas certificações funcionam precariamente, com quantitativo insuficiente de responsáveis, sobrecarregados de demandas e, em alguns casos, desinteressados em atender pontualmente as demandas (ENTREVISTADO DA ASSOCENE).

As instituições emissoras desse documento são: EMATER, Sindicatos dos Trabalhadores Rurais e INCRA. A EMATER e o INCRA dispõem de um corpo técnico que tem dificuldades em atender seus próprios beneficiários. Nesse caso, para atender a demandas de outras instituições, exigiria longo período de tempo, o que implicaria em atraso para efetuar a primeira atividade exigida pela Chamada, que é o cadastramento do público que a instituição irá atender no decorrer do projeto. Com isso, ocorre o não cumprimento do tempo para prestação de contas,que, por sua vez, impossibilita a entrada de recurso financeiro na instituição, visto que o Ministério do Desenvolvimento Agrário só efetua pagamento por serviços prestados e comprovados. Logo, este é um fator que representa a inviabilização do serviço já em sua fase inicial. Fica claro que, sem a entrada de recursos, não há possibilidade de instituições não estatais - que não dispõem de capital de giro - arcar com o pagamento dos técnicos por muito tempo.

Sobre a questão da DAP, Diniz et al. (2011) afirmam:

Ela surge no bojo da necessidade de controle do crédito Pronaf (...) A justificativa era que o Pronaf oferecia "subsídios" e para evitar os possíveis desvios haveria a exigência de um cadastro identificando 0 agricultor. Aos poucos esta identificação começa ser utilizada por outros programas e para outros fins, inclusive para ATER. Assim, pergunta-se: ao centrar e exigir que os beneficiários das chamadas sejam aqueles com DAP, significa que se mantém a visão de desenvolvimento vinculado ao crédito e a adoção de tecnologias modernas? De que desenvolvimento as chamadas, que refletem uma política pública, afinal defendem? Para quais processos educativos 
elas sinalizam para ampliação: da dependência ou da autonomia? (DINIZ et al., 2011).

Quanto à realização e cumprimento das metas estabelecidas de atividades individuais e coletivas, a que mais recebe críticas é a realização do diagnóstico da Unidade de Produção Familiar (UFP). A metodologia prevista é a aplicação de um questionário, com modelo de formulário fornecido pelo MDA. As instituições executoras avaliaram que o formulário é longo, e que o cronograma estabelecido no contrato é inexequível por excesso de diagnósticos em curto período de tempo (ENTREVISTADO DO MMT).

Segundo entrevistados, "os formulários de diagnóstico são mal formatados, com repetições de dados, inadaptado às peculiaridades regionais e questões sem sentido prático". Em alguns casos, a instituição já conhece e atuou na comunidade, mas a meta prevê a realização do diagnóstico e precisa ser cumprida para que entrem recursos financeiros na instituição, mesmo quando a expectativa e necessidade dos agricultores sejam outras, conforme avalia o entrevistado do Centro de Capacitação Zumbi dos Palmares:

\begin{abstract}
A gente prestava assistência técnica no município de Atalaia, em um assentamento que passou um ano e três meses esperando o projeto de ATER ser aprovado para poder reiniciar os trabalhos e eles terem acesso ao fomento. Antes era ATES, quando isso aconteceu às metas eram: seleção e mobilização de famílias; diagnóstico (...) etc. Só que as famílias não entendem dessa forma, não é tão fechadinho assim. Os diagnósticos são importantes, mas esses agricultores passaram um ano e três meses esperando um crédito. Mesmo a instituição já tendo atuando antes nessa comunidade era necessário fazer os diagnósticos porque a meta pedia que fizesse (ENTREVISTADO DO CENTRO DE CAPACITAÇÃO ZUMBI DOS PALMARES).
\end{abstract}

Nas atividades coletivas, estão previstas nas Chamadas reuniões e cursos. Em algumas chamadas, aparecem também dias de campo. Todas essas atividades são divulgadas no edital, com tempo e recurso financeiro definido, sendo que elas nem sempre representam demandas legítimas dos agricultores. Tal discrepância entre demanda real da comunidade e ação prevista de atividades individuais e coletivas nas Chamadas amplia os gastos e requer maior desgaste do técnico para realizar a atividade, podendo provocar desgaste na ação do técnico pela desconexão entre o que se necessita e o que está no papel. A necessidade de homogeneização das ações nunca poderá atender às demandas específicas de cada comunidade.

O acordo que fazemos com as famílias é: precisamos atender às necessidades de vocês, mas deixando claro que precisamos também cumprir as metas. A meta é meio uma, e a demanda outra. Então os técnicos negociam com as famílias, vocês aceitam discutir as duas coisas hoje? Na maioria das vezes eles aceitam então a gente discute o que é emergencial e depois discute aquilo o que é a meta. Ultrapassa o tempo que a meta previa no trabalho, requer mais material, etc. (ENTREVISTADO DO CENTRO DE CAPACITAÇÃO ZUMBI DOS PALMARES). 
Outro grande problema analisado durante a execução dos projetos são os sistemas informatizados oferecidos pelo MDA, para o monitoramento das ações (SIATER) e para a estruturação do banco de dados (SIG@LIVRE). São sistemas ultrapassados, de difícil operacionalização, lentos e pouco interativos. É preciso melhorar os sistemas de informatização de acompanhamento e avaliação, visando sua agilidade e racionalidade, transformando-o em instrumento de larga e fácil utilização pelas entidades executoras (ENTREVISTADO ASSOCENE).

As instituições entrevistadas estão preocupadas em criar sistemas próprios de cadastramento (dos Agricultores Familiares beneficiários),monitoramento e avaliação das suas atividades, visto que os sistemas disponíveis pelo MDA não geram informações básicas necessárias à instituição, como, por exemplo, o número de homens e mulheres atendidos, entre outros dados.

Os achados dessa pesquisa caminham na mesma direção do que afirmou Caporal (2014, p. 43): "Muitos problemas - como a burocracia, a não liberação de recursos nas épocas necessárias ou o atraso na liberação de recursos - que a Lei se propunha a resolver continuam presentes, senão agravados". Percebe-se que as dinâmicas pós-contratos estão se dando de forma problemática devido às exigências das chamadas e às precárias condições em atendê-las, tanto por parte das entidades executoras quanto pelo próprio MDA e sua delegacia no estado.

Segundo os entrevistados, há um reconhecimento de que a Lei de ATER tem contribuído no que se refere à orientação para qualificação dos serviços. Entretanto, as contribuições no campo da efetividade das ações, no caso de Alagoas, ainda são pouco expressivas, como mostrou os dados dessa pesquisa. Segundo Caporal (2014, p.45): "Trata-se, entretanto, de uma política que merece ser avaliada com cuidado, pois é a primeira vez que o Brasil tem uma política de extensão rural instituída por força de Lei”.

De acordo com o entrevistado do Conselho Estadual de Desenvolvimento da Agricultura Familiar e Reforma Agrária (Cedafra), ainda não é possível avaliar se houve contribuições efetivas da Lei, no caso de Alagoas. A percepção inicial deste entrevistado é de que essa Lei ainda tem baixa eficácia, porque não consegue tirar do papel o Art. 2으: (I - "Assistência Técnica e Extensão Rural - ATER: serviço de educação não formal, de caráter continuado") e o Art. $3^{\circ}$, onde são princípios da Pnater: (II - "gratuidade, qualidade e acessibilidade aos serviços de assistência técnica e extensão rural."), tendo em vista que as observações iniciais apontam para a descontinuidade e precária acessibilidade por parte dos beneficiários.

Observando estes achados, à luz da Lei oㅡ 12.188, verifica-se que existe um contrassenso, quando é dito que o serviço é continuado e de educação. Os serviços de ATER através das chamadas públicas não estão cumprindo os princípios, as diretrizes e os objetivos expostos em seus mandatos. As Chamadas Públicas, neste formato, são desconectadas da realidade para o desenvolvimento agrário e agrícola, e não atendem as demandas dos beneficiários e suas representações.

Do que é concebido na Lei de ATER, apontando para outro padrão de desenvolvimento, com base em processos educativos e agriculturas de base ecológica para o desenvolvimento sustentável, pouco se vislumbra nas chamadas de ATER. As ações extensionistas estão fundamentalmente centradas nos aspectos produtivistas, não havendo espaço para processos educativos. Os aspectos culturais, locais e individuais também não são considerados.

Segundo o entrevistado do Movimento Sem Terra (MST), a Lei de ATER definiu as políticas e os programas, o que foi positivo na observação do mesmo. Porém, possui muitas falhas que precisam ser melhoradas. Uma delas é a necessidade de interligação entre as demandas reais dos agricultores e o serviço de 
ATER. O Movimento avalia que "a ATER precisa ser planejada a partir das dificuldades de cada região e não uma coisa única brasileira”.

Algumas instituições consideraram um equívoco, na forma de contratação, o estabelecimento das mesmas exigências para organizações executoras diferentes (poder público, iniciativa privada e entidades da sociedade civil), e que as mesmas estão em condições desiguais de estruturação e de participação. Sobre isso, o entrevistado da Assocene afirma o seguinte:

Outro aspecto, também desfavorável, é o próprio formato das chamadas públicas para prestação dos serviços ao colocar no mesmo ranking de disputa o poder público, a iniciativa privada e as organizações da sociedade civil, esta última em franca desvantagem, embora, reconhecidamente promotoras de inovações metodológicas nos serviços de ATER.

Na mesma perspectiva, é criticado o rigor do processo de padronização dos serviços para grupos sociais com especificidades diferentes (assentados, quilombolas, indígenas, ribeirinhos, mulheres etc.). São impostos procedimentos padrões que têm contribuído sobremaneira para o "engessamento" do princípio estabelecido na Lei sobre a "adoção de metodologias participativas". Isto tem limitado a qualificação dos serviços, dificultado a inovação metodológica e a criatividade das ações de campo. Mesmo em condições de igualdade é preciso reconhecer as especificidades. Nem todos os grupos de mulheres ou de quilombolas possuem a mesma demanda, outras questões precisam ser consideradas, como, por exemplo, as diferenças regionais. Segundo o entrevistado da FETAG, as "Chamadas de ATER não resolvem os nossos problemas relacionados à diversidade do público da agricultura familiar em Alagoas".

Um dos pontos centrais nesse debate da Lei é a questão das metas, analisadas por um lado, como aspecto positivo pela possibilidade de mensurar e quantificar se o serviço atingiu o objetivo fim ou não. Entretanto, torna-se alvo de muitas críticas, porque ao mesmo tempo em que possibilitam a mensuração, engessam um serviço que deveria ser amplo e dinâmico. As metas prevêem quantidade e tempo de cada atividade: se algum agricultor apresentar uma demanda que extrapole o número de visitas estabelecido, e se o técnico desejar atender deverá fazê-lo como trabalho extra. A instituição não é obrigada a fazer mais do que está previsto no projeto.

As chamadas deveriam ser mais flexibilizadas de modo que permitissem a formação conjunta das metas pelas partes envolvidas. O mundo rural é dinâmico, uma série de acontecimentos pode mudar o percurso da ação. É preciso que exista uma carga horária livre para o planejamento das atividades com a comunidade, para que em cima da realidade seja possível fazer uma atuação dentro das demandas existentes (ENTREVISTADO DO CENTRO DE CAPACITAÇÃO ZUMBI DOS PALMARES).

O caminho percorrido pela maior parte das instituições entrevistadas foi aliar metas cobradas pelas chamadas com as demandas dos agricultores. Dessa forma, poderiam ofertar um trabalho com melhor qualidade, mesmo que isso implique em ampliação dos custos e de tempo. Todavia, se uma instituição contratada somente cumprir as metas, assinar ateste e finalizar, sem levar em conta outras questões, ela cumpriu exatamente o papel para o qual assinou contrato. E não há nada que desabone tal procedimento. Segundo o entrevistado da Zumbi dos Palmares, "as chamadas não estão preocupadas com as demandas urgentes das vidas das pessoas". 
O estudo também identificou que o governo de Alagoas não tem contribuído efetivamente para fazer qualquer mudança que garanta bem-estar para os agricultores. As secretarias de estado passam por dificuldades para a captação de recursos federais e beiram a incapacidade nas execuções. $O$ entrevistado do Cedafra afirma o seguinte:

\begin{abstract}
A ATER estatal ainda não se firmou como uma ferramenta importante para a agricultura. Não foi realizado concurso público para contratar profissionais, e por isso não há técnicos suficientes para as demandas do estado. O regime usado, ainda hoje, para o escasso quadro existente, é o de bolsistas. Com limite de tempo do trabalho, os quadros são trocados e a credibilidade no serviço fica cada vez mais comprometida (ENTREVISTADO DO CEDAFRA).
\end{abstract}

Segundo a entrevistada da DFDA, não há empenho do governo do estado em promover a agricultura familiar alagoana, haja vista a estrutura e o ordenamento de despesa destinada ao setor que trata desse segmento no estado.

\begin{abstract}
Aos agricultores de Alagoas são negados seus direitos de acesso a bens e serviços, o que é trágico, porque está se fechando um ciclo onde houve um apoio nas políticas sociais, um volume maior de recursos, um período de crescimento no país e quando se observa o estado de Alagoas, praticamente não se aproveitou quase nada disso. A pergunta é: Quando é que Alagoas vai colocar alguma política social de pé, se conseguiu perder o bonde de uma década de expansão onde as políticas públicas foram valorizadas? (ENTREVISTADA DFDA).
\end{abstract}

Segundo as entrevistas com representantes do Cedafra, FETAG e o MST, pode-se concluir que, para efetivação das ações de ATER: I - urge que o Estado tenha um plano, um projeto de desenvolvimento agrário e agrícola para o meio rural; II - assegure aos beneficiários da Lei o serviço estatal contínuo, e que o serviço não estatal dê conta dos objetivos explicitados em seus estatutos; III - que o CEDAFRA cumpra seu papel principal, que é tratar do desenvolvimento agrário e agrícola do estado.

Por outro lado, segundo entrevistada da entidade estatal, avaliou-se que o Governo Federal contribuiu, através de convênios, para a estruturação do serviço (carros, computadores, etc.), mas o estado de Alagoas não fez sua contrapartida, ou seja, contratar as pessoas, o que também comprometeu a execução das chamadas públicas de ATER e sua execução.

O Governo Federal tem contribuições importantes, mas estas não são efetivadas em Alagoas porque, com o serviço de ATER precário, uma parte dessa demanda deixou de ser cumprida. Como as ONGs são em número pequeno e com um número insuficiente de quadros, o serviço termina por não ficar a contento. As políticas públicas existem, são importantes, mas estão comprometidas: não existe vontade política do governo do estado para executá-las.

$\mathrm{Na}$ avaliação das entidades privadas, o apoio do Governo Federal se restringe às Chamadas Públicas. As instituições analisaram que há uma ausência da convivência institucional desse setor, restringindo-se ao campo burocrático. A convivência com o MDA é relacionada aos contratos, mas poderia ser mais ampla, com condições de discutir processos de capacitação, formação e metodologias. As 
instituições executoras alegam que não se sentem como atores de uma política do MDA, participando apenas como contratados.

Com relação a atuação dos órgãos federais no estado, recomenda-sea integração desses órgãos (DFDA-AL, Companhia Nacional de Abastecimento Conab, Instituto Nacional de Colonização e Reforma Agrária - INCRA-AL, Companhia de Desenvolvimento dos Vales do São Francisco e do Paraíba Codevasf, Ministério da Agricultura, Pecuária e Abastecimento - MAPA, entre outros) para evitar sombreamento de atividades e desconexão das políticas públicas. Essa medida traria melhores condições de contribuições das ações federais.

Pelo que se encontrou nesta pesquisa, sobre a execução dos projetos de ATER, à luz das proposições realizadas pelos entrevistados, recomenda-se: a) viabilização de condições efetivas para o atendimento às demandas por emissão de Declaração de Aptidão ao Programa Nacional de Fortalecimento da Agricultura Familiar(DAP) e Número de Identificação Social (NIS), ou reavaliação da necessidade da DAP para acessar o serviço; b) intervenção e (re)formatação dos sistemas informatizados, que possibilitem a confecção de relatórios técnicos por parte das entidades executoras e o controle social da execução dessa política; c) estabelecimento de fluxos permanentes e padrões para prestação de contas, análise, aprovação e liberação dos recursos; d) condições estruturais na DFDA para executar essas tarefas; e) flexibilidade na padronização de atividades para adequação metodológica à realidade das comunidades atendidas; e) criação de indicadores qualitativos - e não meramente quantitativos - na avaliação dos projetos executados; f) ampla divulgação das políticas e dos programas, o que facilitaria o acesso e a execução; e, g) uma atuação mais presente da delegacia, em Alagoas, junto às entidades executoras.

O apelo dos representantes dos agricultores familiares é que, mesmo com esse modelo cheio de contradições que está posto,

\begin{abstract}
É preciso às instituições se desafiar e se capacitar, para que a assistência técnica seja de fato uma prestação de serviço de qualidade. E possam deixar algo de concreto nas áreas. É preciso difundir o diálogo sobre a agroecologia e sobre os modelos de produção que temos no nosso país, para que essas áreas assessoradas se tornem em possibilidade de enfrentamento desse poder. Que possam produzir de forma diversificada e com qualidade, para mostrar para a sociedade que de fato existe outra proposta, não somente a do agronegócio (ENTREVISTADO DO MST).
\end{abstract}

\title{
5. CONSIDERAÇÕES FINAIS
}

Mediante os achados desta pesquisa, evidenciou-se que o descaso do serviço de ATER para com os agricultores alagoanos persiste ao longo do tempo e resiste às propostas operacionais da Lei 12.188 de 2010.

As promessas da Lei e dos seus gestores parecem vazias ao analisar o percentual de exclusão de $96 \%$ dos agricultores familiares dessa política de ATER, via Chamadas Públicas, que é o principal instrumento de acessibilidade a esse serviço, haja vistas a escassez, precariedade e, por vezes, inexistência do serviço de ATER municipal em Alagoas. Se for considerado que a ATER colabora no processo de articulação e acesso dos agricultores a outras políticas públicas (sociais, produção, comercialização, infraestrutura), na falta de ATER a exclusão das 
famílias agricultoras de outras políticas públicas toma proporções ainda mais devastadoras.

A acessibilidade de apenas $4 \%$ dos agricultores familiares do estado aos serviços de ATER, através das Chamadas Públicas, coloca em xeque o artigo $3^{\circ}$ da Lei, onde o legislador assegura a garantia de gratuidade, qualidade e acessibilidade. Ou seja, a Lei não melhorou a acessibilidade e a qualidade da extensão rural em Alagoas. Obviamente esse fato se deve a uma série de situações, como foi analisado no trabalho.

Esta pesquisa possibilitou um maior entendimento sobre o modo de operacionalização das Chamadas Públicas e seus principais problemas. Permitiu identificar, também, algumas recomendações realizadas pelos atores envolvidos na temática, no estado de Alagoas, que, se consideradas pelos gestores públicos, podem colaborar para a melhoria do serviço realizado junto aos beneficiários. Segundo se identificou nesta pesquisa, o instrumento utilizado pelo MDA, as Chamadas Públicas, carece de sérias e profundas melhorias, sendo fundamental avaliar se os instrumentos utilizados até agora têm sido satisfatórios para cumprir os princípios estabelecidos durante a concepção da Política de ATER em 2010.

E, por fim, possibilitou a constatação da fragilidade que esse Estado experimentou (e ainda experimenta) nas últimas décadas a respeito do serviço de ATER, de modo que os novos instrumentos implementados pela Lei de ATER não contribuíram para minimizá-lo. Para isso, entende-se que é fundamental o comprometimento dos governos Federal e Estadual às demandas da Agricultura Familiar em Alagoas.

\section{REFERÊNCIAS}

BRASIL. Ministério do Desenvolvimento Agrário. Política Nacional de Assistência Técnica e Extensão Rural. Brasília: MDA, 2004.

BRASIL. MDA - Ministério do Desenvolvimento Agrário Lei no 12.188, de 11 de janeiro de 2010. Institui a Política Nacional de Assistência Técnica e Extensão Rural para a Agricultura Familiar e Reforma Agrária-PNATER e o Programa Nacional de Assistência Técnica e Extensão Rural na Agricultura Familiar e na Reforma Agrária Pronater, altera a Lei no 8.666, de 21 de junho de 1993, e dá outras providencias. Brasília, 2010.

BONNAL, P.; KATO, K. O processo contemporâneo de territorialização de políticas e ações públicas no meio rural brasileiro. In: LEITE, S. P. et al. Políticas públicas atores sociais e desenvolvimento territorial no Brasil. Brasília: IICA, 2011. (série desenvolvimento sustentável; v. 4).

CAPORAL, F. R. Extensão rural como política pública: a difícil tarefa de avaliar. In: SAMBUICHI, R. H. R. et al. Políticas agroambientais e sustentabilidade: desafios, oportunidades e lições aprendidas. Brasília: Ipea, 2014. p. 273.

Lei de ATER: exclusão da agroecologia e outras armadilhas - Agroecologia e Desenvolvimento Rural Sustentável - set./dez.2011.

Política Nacional de Ater: primeiros passos de sua implementação e alguns obstáculos e desafios a serem superados. In: RAMOS, L.; TAVARES, J. (Orgs.). 
Assistência técnica e extensão rural: construindo o conhecimento agroecológico. Manaus: Bagaço, 2006. p. 9-34.

. Bases para uma nova ATER pública. Extensão Rural, Santa Maria, n. 10, jan./dez., 2003.

DIAS, M. M. Políticas públicas de extensão rural e inovações conceituais: limites e potencialidades. Perspectivas em políticas públicas, Belo Horizonte, v. 1, n. 1, p. 101-114, jan./jun. 2008.

DIESEL, V; DIAS, M. M; NEUMANN, P. S. Pnater (2004-2014): da concepção à materialização. In: GRISA, C., SCHNEIDER, S. Políticas públicas de desenvolvimento rural no Brasil. Porto Alegre: Editora da UFRGS, 2015.

DINIZ, P. C.; TAVARES, J. L.; ALMEIDA, A. Chamadas públicas de ATER: primeiras reflexões. Recife: UFRPE. 2011. p. 16.

FLEXOR, G.; LEITE, S. P. Políticas públicas: coletânea. SARAVIA, E.; FERRAREZI, E.. Análise de políticas públicas: breves considerações teóricas-metodológicas. Brasília: ENAP, 2006. v. 2.

GIL, A. C. Como elaborar projetos de pesquisa, 5. ed. São Paulo: Atlas, 2010.

INSTITUTO BRASILEIRO DE GEOGRAFIA E ESTATÍSTICA. Censo agropecuário: agricultura familiar primeiros resultados. IBGE: Rio de Janeiro, 2006, p. 1-267. (Versão digital).

LIRA, S. L. S.; Alagoas 2003-2013. Série: Estudos estados brasileiros. Editora Fundação Perseu Abramo. Disponível em: <http:/www.fpabramo.org.br.pdf>. Acesso em: 25/03/2014.

MDA. Disponível em: <http://www.mda.gov.br/sitemda/notícias/mda>. Acesso em: $30 / 05 / 2014$.

MDA - SAF. Disponível em: <http://www.mda.gov.br/sitemda/noticias/safmda>. Acesso em: 30 mai. 2014.

MATTEI, L.; Institucionalidade e protagonismo político: os 10 anos do CONDRAF. Brasília/ DF, 2010.

PRADO, E. Fundamentos teóricos e prática extensionista. Cadernos Técnicos de Veterinária e Zootecnia, Belo Horizonte, 2006.

RUA, M. G. Análise de políticas públicas: conceitos básicos. Rio de Janeiro, 2005. Curso de Aperfeiçoamento em Agroecologia. REDCAPA - Rede de Instituições Vinculadas à Capacitação em Economia e Política Agrícola da América Latina e Caribe.

TEIXEIRA, G. (2009). A proposta de Assistência Técnica Pública e Gratuita para Agricultores Familiares e Assentados - Projeto de Lei ํㅜ 5.665, de 2009, do Poder Executivo: uma análise dos aspectos gerais. Brasília, 2009. (mimeo). 
VASCONCELOS, E. M. Complexidade e pesquisa interdisciplinar: epistemologia e metodologia operativa. 3. ed. Petrópolis: Vozes, 2007. 